\title{
HIDDEN FOUNDATIONS OF DISGUST: REEVALUATING THE EXISTENTIAL NATURE OF DISGUST
}

\section{TOMAS ŠINKŪNAS}

M.A. in Philosophy, PhD student.

Vytautas Magnus University, Kaunas.

44244 Kaunas, Lithuania.

E-mail: sinktom@gmail.com

In spite of the many important findings made within the theory of emotions, scholars still struggle to coherently account for the unique structure of disgust or determine its essence. In contrast to much of the contemporary literature on disgust, I aim to show that, through employing the phenomenological method in his 1929 essay "Disgust" (Der Ekel), Aurel Kolnai was able to grasp the real significance of the phenomenon of disgust. The current study aims to clarify and present Kolnai's insight into the nature of disgust wherein the latter is first and foremost conceived as an ambivalent, multifaceted, but coherent phenomenon. Namely, as a defense mechanism that reacts against the proximity of a disturbing object charged with an ambiguous value of confusion that fluctuates between surplus of life and intention towards death. In order to achieve this goal, I present Kolnai's notion of disgust by first focusing on the foreground of the phenomena of disgust: the essential features of the intentional content of disgust, the object of disgust in particular. I then present and analyze the life-death complex as the underlying structures of the visceral sense of disgust. Lastly, I show how the lifedeath complex relates to the visceral sense of disgust, thereby affirming the coherence of disgust.

Key words: Aurel Kolnai, disgust, emotions, phenomenology, intentional content, visceral sense, the life-death complex.

\section{СКРЫТЫЕ ОСНОВАНИЯ ОТВРАЩЕНИЯ: ПЕРЕСМАТРИВАЯ ЭКЗИСТЕНЦИАЛЬНУЮ ПРИРОДУ ОТВРАЩЕНИЯ}

\section{ТОМАС ШИНКУНАС}

Магистр философии, аспирант.

Университет Витовта Великого, Каунас.

44244 Каунас, Литва.

E-mail: sinktom@gmail.com

Несмотря на многие существенные достижения в рамках теории эмоций, до сих пор для исследователей возникают сложности при попытке дать связное описание уникальной структуры отвращения или определить его сущность. В противовес современной литературе на тему отвращения, я хочу показать, что, применяя феноменологический метод,

(C) TOMAS ŠINKŪNAS, 2017 
в эссе «Отвращение» (Der Ekel) 1929 года Аурел Колнай смог указать на реальную значимость феномена отвращения. В этой статье я стремлюсь изложить взгляды Колная на природу отвращения и прояснить их, учитывая, что он рассматривает отвращение как амбивалентный, многоаспектный, и, тем не менее, связный феномен. В частности, речь идёт о защитном механизме, реагирующем на близость беспокоящего объекта, двойственного в ценностном отношении, колеблющегося между избытком жизни и влечением к смерти. Для того, чтобы изложить и прояснить взгляды Колная, я представляю понятие отвращения, фокусируясь, во-первых, на контексте феномена отвращения: сущностных элементах интенционального содержания отвращения, в частности, на объекте отвращения. Затем я представляю и анализирую комплекс отношений жизнь-смерть как фундаментальную структуру поднимающегося изнутри телесного чувства отвращения. Наконец, я показываю, что комплекс жизнь-смерть взаимодействует с телесным чувством отвращения; таким образом, я связываю вместе разные аспекты отвращения.

Ключевые слова: Аурел Колнай, отвращение, эмоции, феноменология, интенциональное содержание, телесное чувство, комплекс отношений жизнь-смерть.

\section{INTRODUCTION}

Together with a renewed interest in the theory of emotions, in the last ten years there has also been a resurgence in the phenomenological approaches to disgust thanks to the edition of Kolnai's book by Barry Smith and Carolyn Korsmeyer. The general tendency within the scholarship on the theory of emotions is to choose cognitive, physiological, interdisciplinary approaches over others. Unknowingly overlooking discoveries of early phenomenologists, these methodologies continually struggle to account for the experiential and intentional aspects of emotions. Until they start taking phenomenological accounts of emotions $^{1}$ like that of Moritz Geiger, Alexander Pfänder, Adolf Reinach, Max Scheler, Edmund Husserl and others seriously, they will remain incomplete and insufficient. The aim of this article is not so much to debate with current theories of emotion or disgust, but rather to present that which has been unexplained by other scholars in Kolnai's essay "Disgust", namely, key phenomenological insights into the constitutional presuppositions disgust.

Schematically, Kolnai's conception of disgust as it is presented in his essay "Disgust" can be divided into five parts: features of the intentional content of disgust, properties of the disgusting object, underlying sense of disgust which is comprised from the significations of life-death complex, existential intention, and proximity. In his later essay, "The Standard Modes of Aversion: Fear, Disgust and Hatred" written several years before his death, Kolnai lays out a similar

\footnotetext{
${ }^{1}$ See (Ferran, 2015).
} 
conception of disgust, but surrenders the analysis of the constitutive presuppositions of disgust.

In the first part, I present Kolnai's understanding of the standard, visceral sense of disgust that denotes the common level of experiencing disgust and includes disgust aroused by both physical as well as moral objects. Therein I highlight key features of Kolnai's conception of the intentional content of disgust through which the subject relates to the object of disgust. In the second part of this article I select and present key properties from Kolnai's description of the disgusting object. Then, in the following two parts I focus on highlighting and explaining the unclear nature of several obscure properties of the disgusting object (the significations of life, life-death, and death), how pertain to the essence of disgust and to the existential intention of disgust. In the last part, I explain how the underlying structures of disgust form the visceral reaction on the basis of proximity which Kolnai mentions only in several complex passages of his essay.

The strategy of this article is to start with clearer and easier parts of Kolnai's essay such as the intentional contents of disgust and the properties of the disgusting object and then move towards more complex parts of Kolnai's essay such as the significations of life-death complex, existential intention, proximity making explicit those arguments and concepts, which he omitted, left unexplained or mentioned only in passing. Therefore, the overall aim of this article is to present a conceptually coherent structure of Kolnai's disgust which depicts this emotion as a reaction of repulsion against a threat of existence brought about by the proximity of a disgusting object and a simultaneous attraction towards the closeness of the object through apprehending a conflation of significations of intention towards death and surplus of life.

\section{SURVEY OF THE SECONDARY LITERATURE}

With an English translation of Kolnai's text only appearing in 2004, there is still much to be said about his approach to matter of the subject. Authors like Winfried Menninghaus, Daniel O'Shiel, Barry Smith and Carolyn Korsmeyer, Chris Bessemans, Ingrid Vendrel Ferran touch upon various points of Kolnai's conception of disgust, theory of emotions and philosophy.

In "Disgust: Theory and History of a Strong Sensation" (Menninghaus, 2003), Menninghaus gives a brief summary of Kolnai's Disgust. He considers Kolnai's study to be the first comprehensive study of disgust: "dense fifty pages, richer in distinctions than anything before attempted in this field, are still the basic prerequisite for any investigation of disgust" (Menninghaus, 2003, 16). Here 
Menninghaus presents Kolnai's thoughts on the relation between disgust and fear, the moment of attraction and repulsion in the intentional content of disgust. However, Menninghaus is more concerned with the practical side of Kolnai's explanation as he emphasizes Kolnai's presentation of disgusting objects and even faults Kolnai for selecting them on the basis of personal preferences (Menninghaus, 2003, 20). While this is correct, by focusing on Kolnai's seemingly personal selection of examples Menninghaus either misses or ignores the possible conceptual relations and implications of ambivalence, proximity and the ideas of life and death. It is true that some examples taken from Kolnai's personal life are conservative and even homophobic, but such a presentation does not preclude Kolnai from affirming the unitary structure of disgust nor from arguing in favor of its existential significance. Moreover, it could be argued that a subjective selection of examples shows the opposite of Menninghaus' claim - that despite coming from different cultures, people form the same emotion of disgust to various objects, even if they are not aligned with the political corrected of time ${ }^{2}$.

In their introduction to Kolnai's essay "Visceral Values: Aurel Kolnai on Disgust" (Smith \& Korsmeyer, 2004), Smith and Korsmeyer cover the essential points of his conception of disgust and his philosophy. They introduce the phenomenological influences of Brentano, Husserl (Smith \& Korsmeyer, 2004, 59) and situate Kolnai's essay in a broader ethical context (Smith \& Korsmeyer, 2004, 9-14). Additionally, they also take note of the existential significance of disgust but hesitate to approach it (Smith \& Korsmeyer, 24, 19). Instead, Smith and Korsmeyer concern themselves with emphasizing the distinctions between fear, anxiety, and disgust. However, they either do not see the importance and possible implications of this idea, or do not comprehend its grounding value. As it will be argued later in this article, it is in virtue of this particular character of threat that disgust has any significance to the subject and his existential situation.

Bessemans, in his dissertation "Ethics and Value-reality. Aurel Kolnai's Legacy: An Analytic Ethic Based on the Phenomenology of Value-consciousness and Moral Awareness" (Bessemans, 2012), claims that Kolnai's phenomenological analysis of disgust as well as other emotions was a larger part of his project on

\footnotetext{
${ }^{2}$ For more explicit account on disgust and society see Martha Nussbaum's "Hiding From Humanity: Disgust, Shame and the Law" (Nussbaum, 2004), where she, for instance, weighs on disgusts' moral role and its impact on the development of society: "I shall argue, however, that a clear understanding of disgust's thought-content should make us skeptical about relying on it as a basis for law. That skepticism should grow greatly as we see how disgust has been used throughout history to exclude and marginalize groups or people who come to embody the dominant group's fear and loathing of its own animality and mortality." (Nussbaum, 2004, 14)
} 
morality that helped to uncover and identify values within emotions (Bessemans, 2012, 51). Phenomenology was the right fit for his moral philosophy, since Kolnai, as well as other value-realists like Max Scheler, Nicolai Hartmann and others, argued that values have objective existence, independent of subjects that experience these values ${ }^{3}$. They thought that it is possible to disclose them through investigating our experience: “... to grasp or know values, the subject needs to be sensible to value, as human beings are, and he insists on values laying a claim upon us. Kolnai shall name this relation between sensibility and the awareness, and in a sense the being subjected to values, the moral emphasis" (Bessemans, 2012, 59). Furthermore, Bessemans claims that one of the key aims of morality was the preservation of those values. A reaction of disgust is an attempt to preserve those values. Daniel O'Shiel, in his article "Kolnai's Disgust as Violation of Value" (O'Shiel, 2015), argues in a similar fashion that disgust is a reaction against such violations. In the concluding part of his essay he says:

In short, we state that there is always some offended value underlying any disgustreaction, even the most basic. For if I say "it stinks", this implies I prefer, or value, pleasant smells; and if I say "that's filthy", it is because I like my own conception of cleanliness. Ultimately this is because we all value life in particular, specific ways; and we react violently when the phenomena of the world run counter to, and even invade, such ideals. This explains the universality of disgust (everyone has values, founded upon a basic "life-conception"); but also its great diversity (particular, concrete values vary enormously). (O’Shiel, 2015, 38)

Here O'Shiel says that in order for something to violate or disturb there has to be something at stake. In the visceral sense of disgust, a positive idea of life is tackled by a negative idea of life and it creates a ripple in the subject's existence thus arousing a defensive reaction. O'Shiel correctly notes that in Kolnai's view, a positive idea of life is one of disgust's underlying structures. However, O'Shiel mostly emphasizes the moral aspect of disgust and its significance, rather than its constitution. In contrast, much of my article deals with trying to account for how conceptually the unitary structure of disgust hangs together and how ideas of life and death underlie this structure of disgust.

Ingrid Vendrel Ferran, in her many publications like "The Emotions In Early Phenomenology" (Ferran, 2015), "Die Emotionen. Gefühle in der realistischen Phänomenologie" (Ferran, 2008), as well as her introduction and Spanish

\footnotetext{
${ }^{3}$ Bessemans makes a similar claim his article "A Short Introduction to Aurel Kolnai's Moral Philosophy" (Bessemans, 2013).
} 
translation of Kolnai's essay "A. Kolnai: Asco, Soberbia, Odio" (Ferran, 2013), depicts many important aspects of Kolnai's philosophy. In the "The Emotions in Early Phenomenology" (Ferran, 2015) she situates Kolnai's research within the early phenomenological movement stressing Scheler's influence on Kolnai emphasizing their difference with Husserl's phenomenology, ${ }^{4}$ namely, the focus on the description of the object rather than on the conditions of how the object appears to the subject.

She also claims that early phenomenologists subscribed to Franz Brentano's view that "emotions depended on cognitive acts." However, in contrast to Brentano, they emphasized the affective dimension of human experience over the cognitive (Ferran, 2015, 354). If Bessemans took preservation of values to be one of the main aims of Kolnai's moral philosophy, then Ferran maintains that values are not graspable by the means of reason but in a similar way we see or hear. There existed two different approaches within the early phenomenologists as to how they are graspable: ones that took emotions and feelings of value to be separate and others, that took them to go hand in hand. Kolnai subscribed to the latter: "feeling of value is also a way of experiencing ourselves in an emotional experience" (Ferran, 2015, 367).

In her book on emotions „Die Emotionen. Gefühle in der realistischen Phänomenologie“, on which her article "The Emotions in Early Phenomenology" is based, Ferran (2008) allocates a separate section for Kolnai's conception of disgust. As other scholars, she notes all the important moments in Kolnai's essay: she shows differences between fear and disgust, emphasizes the graphic character of disgust, the importance of proximity and the paradox of ambivalence, its ethical significance, etc. In agreement with Menninghaus, she criticizes Kolnai's psychoanalytical character, the example of lying in disgust, and other things (Ferran, 2008, 231-238). Similarly, in “A. Kolnai: Asco, Soberbia, Odio", Ferran (2013) emphasizes the usefulness of phenomenology in qualifying, delimiting, creating taxonomies, analyzing the consequences of disgust. Ferran then talks about Kolnai's aim to describe three important modes of aversion: disgust (Ekel), pride (Hochmut), hate $(H a \beta)$ and argues that all three emotions are defensive reactions that have similar structures, since they provide a possibility of ceasing

\footnotetext{
${ }^{4}$ Dunlop, in his introduction to the collection of essays dedicated to Kolnai's philosophy "Exploring the World of Human Practice" (Dunlop, 2004) also takes note of this important distinction. In a footnote he explains: "This is poles apart from Husserl's obsession with "constitution", and from anything to do with existentialism, but close to the method of Pfänder, Reinach, Hildebrand and the early Scheler." (Dunlop, 2004, 13)
} 
positive relation with an object or the world ${ }^{5}$. Lastly, that Kolnai's thoughts on disgust are original since he connects it neither with biology nor aesthetics ${ }^{6}$, but with morality and ethics.

Ferran, Smith and Korsmeyer, Mennighaus, Bessemans say several things which I am bound to repeat whilst reconstructing Kolnai's argument. One thing they neglect, I will argue, is the importance of the secondary intention of disgust, and fail to articulate the importance of ideas of the surplus of life, intention towards death and their role in forming the essence of disgust by focusing on the psychoanalytical nature of these ideas.

\section{THREE ESSENTIAL FEATURES OF THE INTENTIONAL CONTENT OF DISGUST}

Phenomenologically, the visceral sense of disgust can be divided into two essential parts: the intentional content of disgust and the object of disgust. In the following part, I concentrate on the three essential features of the intentional content of disgust: the direction of the intention, the ambivalent nature of the intention, and the moment of proximity.

In Section 2 of his essay, Kolnai claims that the intention of disgust is primarily directed towards the non-essential properties of a disgusting object ${ }^{7}$, in distinction to being directed to the object itself as a whole. Common experience attests to that. In the case of a cockroach, for instance, it is neither its species that causes us unease, nor its brilliant adaptive mechanisms that have enabled these

\footnotetext{
${ }^{5}$ For purposes of this article, I believe it is sufficient to refer to two essays: "Disgust" and "The Standard Modes of Aversion: Fear, Disgust, and Hatred". Kolnai's studies of other modes of aversion on pride „Der Hochmut“ first published in 1931 or hate „Versuch über den Haß“ first published in 1935 (both in the Philosophisches Jahrbuch der Görres-Gesellschaft) are not very useful whence analyzing disgust. On the one hand, Kolnai advocates for many similarities between fear and disgust, which helps him delineate and separate disgust not only from fear but also from other emotions. On the other hand, his other studies on pride and hate are focused on the moral aspect of those emotions. His other works, such as his collection of essays "Ethics, Value, and Reality" (Kolnai, Williams, Wiggins, McAleer, 2008) mostly deal with the political, moral character of his philosophy, which is covered by Ferran, Bessemans, and other commentators.

${ }^{6}$ In "Aurel Kolnai's 'Disgust': A Source in the Art and Writing of Salvador Dalî" (Radford, 2004), Robert Radford emphasizes aesthetical dimension of disgust and Kolnai's influence on Dalí.

${ }^{7}$ Kolnai designates the non-essential properties of the disgusting object as features of a disgusting object or as so-being (Sosein in German). The idea of Sosein more literally is translated as a kind of suchness that is the being of the object. Barry Smith and Carolyn Korsmeyer explain it as follows: "[t]he intentionality of disgust [...] is directed more to the Sosein, the 'so-being' of its object, that is, to the qualities of the object as they are presented to our senses - its features, traits, characteristics" (Smith \& Korsmeyer, 2004, 9). For purposes of clarity, I will use the expression "non-essential properties" in order to designate the features of the disgusting object, so that they are not confused with other features of disgust, such as the features of the intentional content of disgust.
} 
insects to survive for millions of years, nor is it even the cockroach simply as an insect. Rather, it is its pointy, brown antennae, its uncharacteristically alien-shaped head, and the frantic, tiny movements of its feet that conjure a sense of disgust as it creeps around the room. Or, in the case of being near the rotting stump of a tree that has become infested with bacteria, fungi and insects, the stump itself elicits nothing special. However, one begins to experience disgust in the perception of worm infested wood, the dullness of the color of the bark that shows the loss of the tree's vitality, the slow, orchestrated feast of beetles, bugs, ants, termites, vermin and mushrooms along with the feeble appearance of the wood.

Kolnai further distinguishes fear from disgust, which helps to clarify the nature of the latter. The initial direction of the intention in disgust is the same as in fear - towards the non-essential properties of the disgusting object ${ }^{8}$. Nevertheless, the element of danger is lacking in disgust (Kolnai, 2004, 41). Even though, the object of disgust has the capacity to become threatening through being infectious or poisonous, it does so only secondarily ${ }^{9}$. Initially, by intending a disgusting object, we are directed towards the non-essential properties of that object. And, instead of posing a direct threat, the disgusting object "provokes." The subject responds to the provocation through a visceral curiosity.

This particular capacity to provoke and repulse, beset by the directedness of the intentional content of disgust, is identified by Kolnai as the moment of ambivalence (Kolnai, 2004, 42). Kolnai brings up several arguments in support of the moment of attraction that are found within the intentional content of disgust and revolve around the possibility of coming into contact with the object of disgust. These arguments relate to the properties shared by all the objects of disgust, insofar as they are organic and have the possibility to be eaten, smelled, or touched (Kolnai, 2004, 43).

According to Kolnai, the moment of attraction can be highlighted through inspecting the difference in how the emotions of fear and disgust are terminated (Kolnai, 2004, 39). In fear the subject avoids the object until it becomes non-

\footnotetext{
${ }^{8}$ In his later essay, "The Standard Modes of Aversion: Fear, Disgust and Hatred", Kolnai maintains a similar position: "Disgust, in contrast with fear, bears exquisitely on Sosein - the sensible and perceptible nature of things, as distinct from their causal efficiency and impact." (Kolnai, 2004, 99-100)

9 In his book on disgust "Yuck!" Daniel Kelly (2011) argues that the contemporary understanding of disgust has been molded from two separate evolutionary adaptations to environment: a poison mechanism that safeguards the subject from ingesting toxic food and a parasite mechanism that makes the subject avoid contact with possible carriers of disease. By grounding his main thesis on the coincidence that some disgusting objects are toxic and contagious, Kelly fails to identify the conceptual ground needed to differentiate between a dangerous object and a disgusting object.
} 
threatening. The perception of the threatening object in fear is kept to a minimum, as it is only required by the subject to first identify the threat and then to validate the absence of that threat. In "The Standard Modes of Aversion", Kolnai specifies the difference between fear and disgust: "It is not the spatial proximity of the feared object but the agent's being actually or virtually exposed to its impact that matters" (Kolnai, 2004, 97). In disgust, there is a much more attentive relation between the subject and the object. Usually, repulsion signifies the end of the communion between the object and the subject. However, if it fails to do so, then a "probing" of the object and its non-essential properties ensues, leaving the subject in a confused state of disgust (Kolnai, 2004, 39).

Reactions like shuddering and quivering in the presence of a disgusting object attest to the moment of ambivalence also. As responses to a disgusting object, these reactions arise from a possibility of touching, smelling, tasting the disgusting object (Kolnai, 2004, 43). Repulsion towards the disgusting object yields a physical reaction, even in cases of morally disgusting objects. However, the defense reaction is not solely determined by the intensity of disgustingness, but also by the investment of attention into the disgusting object. In most cases of disgust, there is a tendency to be curiously engrossed by the sight of the disgusting thing that is presupposed by the initial contact with the disgusting object. In such cases, the subject reacts with repulsion not only against the disgustingness of the thing, but also against his own ill-fated fascination with the object that augments the intensity of repulsiveness. Hence, the reaction of repulsion and false infatuation in particular yields shuddering, quivering, or trembling.

It can be said now that in Kolnai's view, every disgusting object, whether it is a piece of putrefying flesh, a swarm of bugs, worms, or whatever, begins with a moment of confusion. Nevertheless, having one's attention captivated by the gruesomeness of the disgusting object should not be confused with the attention required for the initial perception of the object. It is not the case that the object is intended and then repulsion ensues. Rather, the object is intended, and then a moment of confusion (attraction and repulsion) ensues depending on the circumstances. There is neither a primary attraction, nor a primary repulsion; nor strictly a strong sensation of repulsion or an intermingling of the two. Each case depends on particular circumstances. In strong cases of disgust, attraction is absent or infinitesimally small, whereas repulsion is overwhelming. In other cases, however, the opposite is true. Hence, the amount of attraction and repulsion fluctuates from case to case.

Were it not for the moment of attraction, disgust would not possess the dramatic character that it has. It would simply be a matter of disinterestedness, of 
indifference. Paired together with the moment of repulsion, attraction creates a dramatic effect by leading the subject to doubt his own judgment, even his own will, and to shiver from the possible physical or mental hold of the disgusting object. Even if repulsion is the prevailing response in most cases of disgust, the attraction of the possibility of eating, touching, or getting closer to the disgusting object always essentially accompanies this repulsion.

Lastly, throughout his analysis, Kolnai highlights proximity (Nähe) as a particularly important aspect of the phenomena of disgust that does not strictly belong to the emotion of disgust nor to the object of disgust, but is an external circumstance that unites both. He identifies several meanings of proximity: an occasion, as well as a measure of distance. Importantly, Kolnai identifies proximity as the main problem in characterizing disgust, since proximity constitutes what he calls the paradox, or the challenge of disgust (Kolnai, 2004, 42). More precisely, this paradox raises the following question: why does a disgusting object have to be near someone, if we know it to be repulsive? There is no need for it to be near someone at all; in fact, the disgusting object is always too close. Proximity, as it will be seen later, ties a knot between the disgusted subject and the disgusting object. Through proximity, on the one hand, the subject is attracted to and repulsed by the object and, on the other hand, the object attracts and repulses the subject. By uniting two opposites, proximity poses the challenge (Herausforderung) or the paradox of disgust.

Altogether, the aforementioned features of the intentional content of disgust are essential and have several implications. The intention of disgust is always directed at the non-essential properties of the disgusting object. The subject is repelled but also attracted to the object of disgust. The idea of proximity is a complicated yet central idea in many aspects of which I have yet to uncover. To gain a better grasp on the visceral sense of disgust, in the following part I present an analysis of the object of disgust.

\section{THE OBJECT OF DISGUST AND ITS PROPERTIES}

On the other side of the phenomena of disgust is its object. Kolnai presents different kinds of disgusting objects of a physical nature, as well as different kinds of disgusting objects of a moral nature, that are broadly speaking mental (geistig) objects, that have or can have moral significance.

First, the paradigmatic, most vivid (with regard to the senses) is disgust at those objects which are putrefying (Kolnai, 2004, 53). Second, seemingly useless, 
stinky bi-products of the body (Kolnai, 2004, 54). Third, objects that are or look like bodily secretions, which become disgusting due to their excessive, aimless production of that which is seemingly useless (Kolnai, 2004, 54). Fourth, proximal objects with an overemphasized moment of stickiness or adherence. For instance, dirt (Kolnai, 2004, 55). Fifth, those insects, arachnids, reptiles, arthropods and the likes that exhibit features such as sliminess, pointy antennas, sticky feet, overabundance, unpleasantness and the like (Kolnai, 2004, 56). Sixth, normal eatable foods that have qualities that resemble putrescent qualities of food, like blue cheese, fried scorpions or natto (Kolnai, 2004, 59). Seventh, the human body and especially the proximity of an unwarranted body that is apprehended via some unpleasant contact smell or even gaze (Kolnai, 2004, 61). Eighth, living beings that are perceived as being excessively fertile, as in cases of fish-spawn and vermin multiplication (Kolnai, 2004, 61). Finally, disgust at diseases or bodily deformations. For instance, disgust at someone who has smallpox, or someone who has a hunchback (Kolnai, 2004, 62).

The moral, mental objects of disgust are of five kinds, according to Kolnai. First, excessive satiety, which is aroused through the repetition of a pleasurable act or event, an experience of having had too much. Kolnai gives an example of being disgusted by sweets (Kolnai, 2004, 63). Second, excessive vitality in cases where it is misplaced or at least seems to be misplaced. For instance, someone who fidgets all the time (Kolnai, 2004, 65). Third, an indifference to truth and falsehood. For instance, a person unable to clearly express his or her own thoughts or constantly lies (e.g., a pathological liar) (Kolnai, 2004, 68). Fourth, corruption that corresponds much better to the conventional comprehension of lying and dishonesty. It is more deliberate than an indifference to truth. Fifth, moral softness that indicates an inability to decide on ethical matters (Kolnai, 2004, 71).

Several properties can be abstracted from the aforementioned objects: the possibility of adhering to, being made up of organic matter or of being associated with it, and most importantly signifying a surplus of life (Lebensplus) and an intention towards death (Todesintention). Drawing an exhaustive list is not as important as highlighting the common properties between the two different types of disgusting objects in the following pages as they highlight essential parts of the visceral sense of disgust.

All the physical objects that are disgusting are made up of organic matter ${ }^{10}$ or at least appear to be so (Kolnai, 2004, 30). In order for an object to be

\footnotetext{
${ }^{10}$ Naturally, there is a class of inorganic things that seem to be disgusting. For instance, rusty metal, smelling hot plastic, small shards of glass and the like. Kolnai does not provide a direct
} 
disgusting, organic life or traces of it have to either be directly present or be represented (as in mirrors, pictures, or movies). Morally disgusting objects are also associated with organic matter, in spite of the fact that they are immaterial. Indeed, all objects in the moral sphere have ethical or moral significance - and sometimes concrete implications - for living beings. Hence, even if they are not made up of organic matter, they are at least related to it by association. Mental objects do not exemplify signs of corrosion putrefaction, since it is a process that occurs in metals, which are inorganic. However, there is such a thing as the putrefaction of morals.

Disgusting objects appear damaged, carious, or deformed in relation to a previous state. Imbalanced functioning is not as important here, since the object of disgust is not necessarily meant for any practical use. Rather, the arousal of disgust is closely tied to the perception of an envisaged contrast between the deformed state of being and the object in an ideal, healthy state. Similarly, moral acts are disgusting when they are perceived as being inappropriate or out of place, such as talking during a moment of silence. This mostly refers to a deviance in character or an abnormality within an individual's moral scheme. The subtle difference between the physical and moral spheres is that misplacements in the moral sphere are more susceptible to moral judgment. For instance, a rotting apple is morally insignificant, but a person quietly smirking at a funeral is not ${ }^{11}$.

answer to this objection, but several claims can be made in support of his argument. First, under particular circumstances all inedible and inorganic things can become disgusting. However, this does not make them disgusting per se, since the quality of disgustingness does not reside within them. The rusty metal, for example, can become disgusting only if we lick it, whereas a putrefying stomp or a dead body - always is. Second, there also exists a state of consciousness where every physical, moral and even metaphysical thing is disgusting. However, this particular state of consciousness is closer to what we designate as nausea than disgust and is illustrated by Jean-Paul Sartre in "Nausea" (Sartre, 2007, 126-128).

${ }^{11}$ Reacting with disgust to an "abnormality" creates a constant point of controversy within the scholarship of emotions, disgust as well as of modern society. The subject of disgust is usually criticized as being "outdated" or at least "irrelevant" when it comes to ethical matters due to this particular feature. To be clear, the perception of divergence implies an existence of two poles: an encompassing pole of "normality" or that which is considered to be "normal" and a contrasting and less powerful pole which falls out of the boundaries of the idea of "normal," therefore defining that which is "abnormal." In simple cases of disgust like a rotting apple, or misconduct at a workplace, disgust is appropriate, but one can only begin to imagine how it becomes a catalyst for social tensions whence the perception of "normal/not normal" is applied to "able/disable," "heterosexual/homosexual," "yellow/white/black," "neurotic/schizophrenic," and so on. For this reason, the immediate sense of disgust, especially perceiving a contrast between "normal/not normal" cannot be allowed to support such judgments, since it bypasses all the important social norms, sometimes even basic human rights. At the same time, it does not mean that disgust has to be denied any involvement in ethical affairs - it has to be tamed and applied where appropriate. 
Disgusting objects trigger perceptions of a chaotic contrast between an intention towards life (Lebensintention) and an intention towards death. Kolnai uses the terms "life," "surplus of life" (both of which he uses almost in the same sense), and "death" in order to refer to the many facets of this property.

According to Kolnai, this chaotic contrast between life and death is clearest in putrefying objects (Kolnai, 2004, 73). In these instances, that which is already dead or is on the verge of dying is covered with other living beings, such as microbes, fungi, and worms that eat away at whatever organic matter remains of the decaying object. At the same time, the perception of excessive vitality and of overemphasized liveliness is short-lived as in the long run it leads towards a cessation of existence.

Kolnai also draws attention to this contrast in his presentation of objects of moral disgust. In this case, the contrast is between a standard, proper, efficient way of life and a deviation from this standard. This contrast does not signify a onetime error, a lack of better judgment or a misstep, but tendencies that are detrimental towards a given standard way of life. Thus, mental objects that arouse moral disgust exhibit a complete lack of purpose or a wrong function, which manifests as the object's intention towards death. It does not direct the particular object towards death but rather exudes an underlying devolution in the object towards decay.

The presentation of the key features of the disgusting object is essential for making the transition to the analysis of its underlying structure. At this point, it can be said that there is a correspondence between the intentional content of disgust and the object of disgust. Namely, in the visceral sense of disgust, the subject is simultaneously attracted and repulsed towards the non-essential properties of the disgusting object (moral or physical) wherein life and death are signified. Hence, both the intentional content as well as the properties of the disgusting object seem to correspond to the same sense of disgust. However, it is unclear what lies beneath the visceral sense of disgust. To gain insight into this structure, I suggest to turn to what Kolnai calls a "reflexive" look at disgust.

\section{FUSION AND CONFUSION: THE LIFE \& DEATH COMPLEX}

In the following part, I present and explain Kolnai's conception of "life", surplus of life, and the intention towards death, their relation to the subject as the underlying structures of disgust wherein ordered, balanced life is contrasted with

For a more investigative analysis see Daniel O'Shiel's article "Kolnai's Disgust as Violation of Value" (O’Shiel, 2015). 
unordered versions. I show how in disgust, which is under the domain of the unordered, the life-death distinction gets blurred, and how a paradoxical situation of being simultaneously attracted and repulsed by the disgusting object arises.

Kolnai interprets the concept of life as positive and ethical in the broadest sense and introduces this conception through the term framework (Gerüst), which is defined as "a word in which there is indicated the full significance to the individual life of the non-organic, of what is as it were schematically adumbrated" (Kolnai, 2004, 72). The idea of life refers to an existence where the the intellectual, rational part of the mind prevails over passions, emotions and basic needs of the body. In this context, it does not encompass or habituate bodily needs, irregular cravings, or outbursts of anger.

Commonly, a positive, ordered conception of life is contrasted to an unordered, negative conception of life, the latter being unproductive, violent, irrational and led by the passions or a weakness of the will. With respect to disgust, the case is different. The idea of an ordered life is opposed to the lifedeath complex, which encompasses the conflation of surplus of life and intention towards death.

At first glance, the concept of surplus of life that is perceived within a disgusting object denotes a perception of an intention through which the object exhibits an excessive amount of movement, regeneration, liveliness, and the like. The concept of the surplus of life refers to the vitality of the disgusting object, which creates an impression of that object's strength and health, attests the object's inability to contain or limit the overabundant amount of energy. What counts the most at this moment is not the actual result but the way in which the object appears as directed towards senseless, limitless, boundless multiplication and growth (Kolnai, 2004, 73). The perception of the perverted intention towards life found within the signification of the surplus of life signifies a particularly unusual aspect of an object - a failed attempt to express liveliness through a disproportionate leap from the dysfunctional to the functional.

The apprehended signification of surplus of life in the disgusting object attracts the subject towards the disgusting object. It attracts not due to its exemplary nature of showing how certain life forms can survive in hostile environment. The attraction, according to Kolnai, is based on the seemingly appealing appearance of the disgusting object conveyed through the surplus of life (Kolnai, 2004, 77). The non-essential properties exhibit nutritional qualities and therefore the disgusting object appears in a similar fashion to that of edible objects. 
Further inspection of the disgusting object reveals a nuanced and particular moment within the signification of surplus of life. In a matter of moments, it becomes evident to the subject that behind the pretentious and boundless fluidity of the surplus of life the inanimate interior of the disgusting object is hidden. Even if, the disgusting object appears to be possessed by a desire to excessively multiply, even if it seems to be at the peak of its liveliness, it is in reality burning away last pieces of its own life force. Thus, the emphasis shifts within the signification of the surplus of life and brings to the fore a different aspect of the disgusting object - its decay. Though, still in the context of excessive liveliness. The switch towards the signification of the intention towards death occurs whence the deathly aspect begins to dominate the liveliness of that particular object.

Hence, on the other side of the life-death complex lies an intention towards death. Within this signification the emphasis shifts from the superfluous flourishing within something that is en route to death to that which is already dead, even if a meaningless specter of life is somehow able to find shelter: "For at first there always lies herein a life that is impoverished in its dimensions in spite of the moment of over-emphasized 'fullness'; there is to be found a desertion of the aggregate structure of life, an effervescent pursuing of one particular line of development" (Kolnai, 2004, 74).

In contrast to signifying boundless multiplication, the disgusting object is now perceived as imprisoned by the process of decomposition. As germs metamorphose on the dead tissue of the disgusting object, the object is pervaded by an intention towards death which in an aggressive fashion threatens to transmit onto the subject the quality of disgustingness. However, in contrast to fear, the aggressive fashion of this particular signification lacks the strength necessary to arouse the same level of concern for one's safety.

In contrast to disgust, fear signals an immediate and direct threat to the subject's physical or mental existence. For this very reason, the intention of fear is directed at two things simultaneously. On the one hand, the intention of fear is directed to the object which is threatening and can signify a varying level of possible threats (from a simple possibility of being harmed to a direct threat to one's existence). On the other hand, the intention of fear is also directed to the subject as a signal to take action in order to avoid possible damage (Kolnai, 2004, 36).

In disgust, the intention towards death presents a "threat" to "transfer the decay and decomposition, effective within themselves, to everything with which they come in contact" (Kolnai, 2004, 75), but lacks strength to arouse fear. It is perhaps better understood as a pseudo-threat, insofar as it lacks the essential 
property of a threat - detrimental consequences ${ }^{12}$. The pseudo-threat emitted by a disgusting object resembles a mild case of fear:

\begin{abstract}
One fears that one might become soiled by the object, or stuck to it, maybe even that one might enter into some form of lasting communion or somehow injurious relationship with it whereby our personality will become stained. We do not however fear that we might die or be gravely harmed physically (thus the fear is not one which rests on an intention towards our own total condition), nor that we might become so united metaphysically with the object that one might lose oneself in it. (Kolnai, 2004, 76)
\end{abstract}

The reaction of repulsion, then, ensues as a defense mechanism against the aggressiveness of the signification of the intention towards death that rests upon the subject's conception of deathly matters (Kolnai, 2004, 77). Without comprehending his own ability to decay the subject would not defend against it in a manner specific to disgust. In Kolnai's view, the specificity of this defense indicates, that there also exists an existential intention within the phenomenon of disgust, through which the existential situation of the disgusted person is intended. I will come back to this idea in the following part.

For now, it can be said that the disgusting object falls within the scope of the unordered idea of life, but it cannot be perceived as strictly signifying only the surplus of life or only the intention towards death. The concepts of surplus of life and intention towards death highlight two separate sides of the same life-death complex. In reality, they always chaotically intermingle within the non-essential properties of the disgusting object and it is almost never clear where one ends and the other one begins.

In the forefront of the phenomenon of disgust, the primary direction of the intention of disgust is towards the non-essential properties of the disgusting object. The subject is attracted to the disgusting object, because the latter captivates the subject through presenting itself in an appealing fashion. And, on the other hand, the subject is repulsed, because the signification of intention towards death threatens to transfer the decay unto the subject.

Put differently, the object of disgust fascinates the subject the same way a good magician fascinates the audience: the object of disgust is able to cause a perfectly orchestrated illusion of facing certain death. The sad truth about the disgusting object is, of course, that in the end, the illusion is its reality — there is

\footnotetext{
${ }^{12}$ Naturally, disgusting objects can be dangerous, poisonous, but danger does not belong to the essence of a disgusting object.
} 
no escape. Taken together, the surplus of life and intention towards death attract and repulse the subject. This moment poses what Kolnai calls the most important challenge or paradox of disgust. We thus arrive at this particular question - how two different intentions are represented within the foreground of disgust.

\section{THE EXISTENTIAL INTENTION OF DISGUST}

There are two important constituents of disgust that have been left unexplained $^{13}$ : the existential intention and proximity. In this section, I will focus on presenting the existential intention of disgust, which is intended through the pseudo-threat and facilitates the moment of reciprocity between the subject and the disgusting object. First, I will briefly recount what has been said about the structure of the phenomena of disgust before. Second, I will show how the subject perceives the pseudo-threat found within the disgusting object and how it forms a reciprocal relation with the subject.

A further nuance of the phenomena of disgust is introduced by Kolnai through the idea that there exists an existential intention in the background of the phenomena of disgust ${ }^{14}$. Kolnai says several things about the intention. First, that the word "existential" does not mean "reflective". Naturally, the intention of disgust, as any other intention, can be directed secondarily (or simply redirected) towards the subject's own constitution on the basis of possible similarities. Apprehending the similarities between the composition of the disgusting object and the human body can trigger anxiety, fear, even horror. In contrast, the existential intention produces an immediate, though specific and mild, concern for one's own existence (Kolnai, 2004, 77) by indicating the possible organic decay of the human body:

\footnotetext{
${ }^{13}$ O'Shiel, Ferran, Menninghaus, Smith \& Korsmeyer, take note of the ambivalent nature of disgust as well as disgust's relation to life, death. For example, Menninghaus notes: "By contrast, the complex relationship of disgust to life and death receives more attention. The disgust reaction aims to protect us from contamination, defilement, and death, but is always already exposed to the immediate proximity of these things, a proximity that "is poised to crush us." Moreover, there is a disgust not only in the presence of the decaying corpse, but "in the presence of rampant life" itself." (Menninghaus, 2003, 18) Nevertheless, they are reluctant to analyze important passages of "Disgust" found in pages 72 to 80 and look deeper into the relation between the subject and surplus of life, death.

${ }^{14}$ Ferran, as well as Menninghaus neglect this idea by clinging to the difference between the intentions of fear and disgust (former is doubled: directed to the object and to the subject, whereas disgust's intention is directed only towards the object). For instance: „Der Ekel richtet sich nur ,nach außen' und intendiert ein Objekt in seiner sensorichen Fülle. Im Ekel werden demnach nicht Existenz und Sicherheit der eigenen Person intendiert, sonder nur die Oberfläche und die Berührungseben mit dem ekelhaften Objekt" (Ferran, 2008, 233). Kolnai argues says, that the intention of disgust is returned to the subject.
} 
The ugly face of death which seems to present itself to us in every disgusting object reminds us of our own affinity to death, of our inevitable submission to it, of our secret death wish. Thus it warns us not, as with the skull and the hourglass, of our existential inability to escape from death - similar to the experience of the merciless approach of the hour of his execution of one who has been sentenced to death - but rather of the subjection to death which is essential to us, of the directedness towards death of our life itself, of our existence as made up of material which is consecrated to death; one could also say that we are drowned within a material which is already prepared for decay. (Kolnai, 2004, 78)

The defense is raised against the disturbance of existence, which in the case of disgust comes about through an alien object and is a reaction against the signification of intention towards death found within that alien object. The defense reaction against the pseudo-threat is triggered through apprehending the signification of intention towards death within the non-essential properties of the disgusting object. The existential situation of the subject is intended in this instance. It neither negates nor interrupts the attraction and repulsion of the disgusting object, nor the directedness of the intention towards the object, but is rather a result of a disturbance of existence connected to the moment of repulsion. Nonetheless, due to the specific and mild nature of the threat, it fails to become the primary intention.

The existential intention does not have the power to become primary since it is specific, mild and weak, even if the pseudo-threat conceptually has the capacity to signify fear. The classic horror film genre is a testament to that claim. In reality, the typical object of disgust never obtains enough power to produce fear and, due to this weakness, the subject is attracted towards the disgusting object. Therefore, whence apprehending the disgusting object, the subject always turns toward the non-essential properties of the disgusting object, but not toward his own existential situation. Yet, in the foreground of the phenomena of disgust the signification of intention towards death overtakes the signification of surplus of life, even if never completely.

On the one hand, the threatening object that threatens to transfer the quality of disgustingness over to the subject and the subject reacts by moving it away. The absence of the signification of intention towards death would significantly diminish the power of the pseudo-threat, thus resulting in an even weaker reaction of disgust as we find in some reactions to dirt (Kolnai, 2004, 55). Consequently, the existential intention would be weak or unnoticeable, if present at all, as it is directly connected to the pseudo-threat. 
The signification of surplus of life, on the other hand, does attract the subject on the basis of the functional features found within the non-essential properties of the disgusting object (Kolnai, 2004, 77). Attraction prevails in those cases where the signification of intention towards death is overtaken by surplus of life, such as smelly cheeses. However, the existential situation of the subject is not intended.

The key to understanding Kolnai's insight lies in comprehending that even if the signification of the surplus of life is a part of the life-death complex, it still has a different source than the signification of intention towards death. The existential situation of the subject in disgust is intended by apprehending the pseudo-threat through the signification of intention towards death, but never on the basis of relating to the functional aspects of the object.

In the foreground of the phenomena of disgust, the signification of surplus of life is an equally important part of the life-death complex even if it has a difference source than the signification of intention towards death. When the signification of surplus of life is overtaken by the signification of intention towards death it is not eradicated, but becomes less visible. It is always a mixture of both that make up the essence of disgust. The existential intention, even if arranged in the background, facilitates the reciprocal relation between the subject and the object by making the disgusting object relevant as an object that evokes concern for one's own wellbeing, even if mildly and specifically.

Almost fifty years later, in "The Standard Modes of Aversion: Fear, Disgust, Hatred" Kolnai drops the existential aspects of his earlier study: surplus of life, intention towards death. Textual evidence is lacking and therefore it is hard to say whether he opposed this theory altogether, whether he lost interest or simply wanted to keep it short and analytical: "I have nothing to offer but (a) very plain and unexciting thesis..." (Kolnai, 2004, 93). Even though he followed the same position with regard to the essential features of disgust: ambivalence, gustatory and olfactory spheres are primary in disgust, paradigmatic examples of disgust are formed on putrescence of the object (Kolnai, 2004, 101-102).

Nevertheless, in the context of formation of disgust, apprehending, analyzing and highlighting these concepts does not only depend on the state of the object (how decayed or decomposed it is). The significations of the life-death complex do not have the power to arouse a disgusting reaction on its own, unless it is perceived under certain circumstances. Thus, the last question that I shall entertain in my article is as follows: how does proximity of the disgusting object unite the threat issued by the latter with the attraction created by a surplus of life signification into a unitary and immediate visceral reaction of disgust? 


\title{
THE NATURE OF DISGUST
}

The particular challenge of understanding disgust as a unitary defense reaction brings me to the final presentation of this article. The last component of the structure of disgust is the relation of proximity. In the following section I will present proximity, focus on explaining how Kolnai thinks proximity works in disgust and how all the different parts of disgust come together and form a unilateral phenomenon of disgust.

The possibility of coming into contact with the disgusting object carries itself out differently from coming into contact with non-disgusting things: it is not a simple pushing away of an object, but a reaction against the specificity of disgustingness:

\begin{abstract}
But this intention towards existence is not directed simply to one's own situation (one's own survival), as this is subject to causal efficacy of the object, but rather through its proximity - proximity as sensual perceivability, as palpability, as the closeness of functional relation, traffic, communion with the object. (Kolnai, 2004, 78)
\end{abstract}

Within the frame of the phenomena of disgust, proximity encompasses much more than a simple idea of distance between the disgusting object and the subject. Proximity crafts the essence of disgust by forming a bridge between the significations of the life-death complex within the disgusting object and the subject. It acts as a conductor of disgust and facilitates an uncomfortable, nauseating communion between the subject and the object involving a conflation of the significations of the life-death complex. Kolnai defines proximity in the context of its significance and reciprocal relation between the subject and the object in the following way:

For it is this which — as already intimated — first permits us in some way to grasp the matter: this substantial proximity which touches the general properties of our being and at the same time represents in a concentrated manner the specific features of the object giving rise to disgust. (Kolnai, 2004, 79)

Several important things are said here about the essence of disgust. First, he assumes that our existential situation can be influenced by different types of objects. Hence, there are different ways to affect the existential situation (fear, anger, love, etc.), but here, the "general properties of our being" (Kolnai, 2004, 79) are affected by disgust and specifically through proximity. 
Second, Kolnai is referring to significations of the life-death complex as "specific features of the object" (Kolnai, 2004, 79), which are found within the visceral feeling of disgust. If he wanted to refer to all of the non-essential properties of the disgusting object, he would have omitted this specification altogether. However, in the context of disgust and particularly in the context of discussing the formation of disgust, a specification can only denote the significations of life-death complex.

Lastly and most importantly, the idea of proximity accounts for how the significations of the life-death complex of disgust form the visceral feeling of disgust. Reciprocal relationship between the subject and the disgusting object is created through proximity, but not only through one element of disgust. A few lines later, Kolnai elaborates: "the proximity of the object with its quite characteristic intention towards life and towards death, constitutes a unity between the object itself and its announcing of life and death". (Kolnai, 2004, 79)

The disgusting object is experienced ambivalently and reciprocally, since through proximity the object of disgust and the signification intention towards death and surplus of life are united into one apprehension. The significations of life-death complex appear in the most basic experience of the disgusting object, not as fully reflected and comprehended significations of intention towards death and the surplus of life with all of its implications, but as abbreviated apprehensions that are inseparable from the disgusting object. The basic form of experience of disgust as a defense reaction against a threat is retained through proximity that facilitates the abbreviation of the significations of life-death complex ${ }^{15}$.

Therefore, when disgust is aroused by a particular object, it is never a thought about the intention towards death or the surplus of life that strikes the subject, but a provocation. The signification of the surplus of life expressed in an abbreviated manner together with the non-essential properties of the disgusting object fascinates the subject and the intention towards death signified in an abbreviated manner together with the non-essential properties of the disgusting object repulses the subject by emphasizing the existential affinities of the subject. The unitary experience of disgust can therefore be described in the following way. The intention of disgust, which is directed towards the non-essential properties of the proximate object (physical and moral) attracts and repels. The disgusting object provokes and threatens by signifying - through its non-essential properties that are proximate to the subject - life and death in a concentrated manner. The disgusting object

\footnotetext{
${ }^{15}$ This is the essential moment connects the underlying sense of disgust with the immediate, visceral sense of disgust, which I believe, other commentators fail to address.
} 
provokes the subject not simply by being close, but by extending its disgustingness through proximity. Not physically, but in the apprehension of the subject.

For this reason, the subject reacts by seeking to distance himself or herself from the pseudo-threat that emanates from the object of disgust. Otherwise, if the significations of the life-death complex were not apprehended in a concentrated manner, the disgusting object would either arouse a different emotion altogether or it would arouse no emotion at all. Put differently, if the object of disgust did not disturb the subject's existential situation, then a contact with that object would not entail a defensive reaction. But, the fact of the matter is that there is something within the disgusting object that disturbs the "lived existence" (Kolnai, 2004, 73) of the subject against which the subject is forced to react.

In the context of the experience of disgust, the disturbance conjures the significations of life and death. Disgust defends the subject against a partial or mild disturbance aimed specifically, even if mildly, at that subject's existence. Kolnai accurately notes that the formation of disgust as a defense reaction rests on the "affinity of person's feelings with that deathly life" (Kolnai, 2004, 77). Without the idea of mortality, there would simply be no need to defend oneself against a disgusting object. Therefore, in most cases, disgusting objects have the power to disturb by reminding us of our own susceptibility to decay.

On a conceptual level, Kolnai identifies disgust as a peculiar reaction among others, which is intended through non-essential properties of an object that is always too near. However, a deeper analysis of the conceptual understanding of disgust uncovers an implicit structure in the reaction itself. Namely, it is a defense reaction against possible disturbances of our existence. In this sense, the significations of the life-death complex are presuppositions that structure disgust and through a reciprocal relation create the value of disgustingness. The full significance of disgust as a defense reaction is only understood after taking the conflation of intention towards death or surplus of life into account.

\section{CONCLUSION}

Most common experiences of disgust expose an innate ambivalence towards the disgusting object. The closer the subject is to the disgusting object, the more disgusting it becomes. Underneath this experience lies the conflation of the significations of intention towards death and surplus of life that are represented in a concentrated manner by the non-essential properties of the disgusting object. Hence, the object of disgust is always charged with the values that provoke and 
threaten the subject by reminding the subject of his or her own predisposition towards decay.

This article will contribute towards a better understanding of Kolnai's Disgust as it provides an exposition of complicated passages that other scholars have either ignored or deemed unimportant and gives an overview of the structure of the phenomenon disgust. Fundamentally, the structure of disgust and its full account is rather tightly connected to the existential situation of the subject. The last chapter of Kolnai's essay deals with the question of overcoming disgust. It mostly consists of Franz Werfel's poem Jesus and the Carrion Way. I believe it serves to show that the real dilemma of disgust is moral and has to do with the following question: how can we, as human beings, properly embrace the conflation of life and death?

\section{REFERENCES}

Bessemans, C. (2012). Ethics and Value-reality. Aurel Kolnai's Legacy: An Analytic Ethic Based on the Phenomenology of Value-consciousness and Moral Awareness. Leuven: K.U.Leuven, Hoger Instituut voor Wijsbegeerte.

Bessemans, C. (2013). A Short Introduction to Aurel Kolnai's Moral Philosophy. Journal of Philosophical Research, 38, 203-232.

Dunlop, F. (2004). Introduction. In Z. Balázs \& F. Dunlop (Eds.), Exploring the World of Human Practice: Readings In and About the Philosophy of Aurel Kolnai. Hungary: Akaprint Nyomda.

Ferran, I. (2008). Die Emotionen. Gefühle in der realistischen Phänomenologie. Berlin: Akademie Verlag.

Ferran, I. (2013). Aurel Kolnai: Fenomenología de los sentimientos hostiles. In A. Kolnai, Asco, Soberbia, Odio (7-32). Madrid: Editorial Encuentro.

Ferran, I. (2015). The Emotions in Early Phenomenology. Studia Phaenomenologica, 15, 349-376.

Hartmann, N. (1926). Ethik. Berlin: De Gruyter.

Kelly, R. (2011). Yuck!: The Nature and Moral Significance of Disgust. Cambridge, MA: MIT Press.

Kolnai, A. (2004). Disgust. In B. Smith \& C. Korsmeyer (Eds.), On Disgust (27-93). Chicago: Open Court.

Kolnai, A., \& Honneth, A. (2007). Ekel, Hochmut, Haß: zur Phänomenologie feindlicher Gefühle. Germany: Suhrkamp.

Kolnai, A., Williams, B., Wiggins, D., McAleer, G. (2008). Ethics, Value \& Reality. New Brunswick: Transaction Publishers.

Menninghaus, W. (2003). Disgust: Theory and History of a Strong Sensation. Albany, New York: State University of New York Press.

Nussbaum, M. C. (2004). Hiding from Humanity: Disgust, Shame, and the Law. New Jersey: Princeton University Press. 
O'Shiel, D. (2015). Kolnai's Disgust as Violation of Value. In M. Delville, A. Norris \& V. Von Hoffmann (Eds.), Le dégoût: Histoire, langage, esthétique et politique d'une émotion plurielle (25-39). Liège: Université de Liège.

Sartre, J-P. (2007). Nausea. New York: New Directions Publishing.

Smith, B., \& Korsmeyer, C. (2004). Visceral Values: Aurel Kolnai on Disgust. In B. Smith \& C. Korsmeyer (Eds.), Aurel Kolnai, On Disgust (1-25). Chicago: Open Court.

Radford. R. (2004). Aurel Kolnai's "Disgust": A Source in the Art and Writing of Salvador Dalí. In Z. Balázs \& F. Dunlop (Eds.), Exploring the world of human practice: readings in and about the philosophy of Aurel Kolnai (327-331). Hungary: Akaprint Nyomda. 